\title{
Pregnant and Nonpregnant Women in Cape Town, South Africa: Drug Use, Sexual Behavior, and the Need for Comprehensive Services
}

\author{
Hendrée E. Jones, ${ }^{1}$ Felicia A. Browne, ${ }^{1}$ Bronwyn J. Myers, ${ }^{2}$ Tara Carney, ${ }^{2}$ Rachel Middlesteadt \\ Ellerson, ${ }^{1}$ Tracy L. Kline, ${ }^{1}$ Winona Poulton, ${ }^{1}$ William A. Zule, ${ }^{1}$ and Wendee M. Wechsberg ${ }^{1}$ \\ ${ }^{1}$ Substance Abuse Treatment Evaluations \& Interventions Program, RTI International, \\ 3040 Cornwallis Road, Research Triangle Park, NC 27709, USA \\ ${ }^{2}$ Alcohol and Drug Abuse Research Unit, Medical Research Council, P.O. Box 19070, Tygerberg, Cape Town 7505, South Africa
}

Correspondence should be addressed to Hendrée E. Jones, hjones@rti.org

Received 30 August 2010; Accepted 9 February 2011

Academic Editor: Lucy Burns

Copyright ( 12011 Hendrée E. Jones et al. This is an open access article distributed under the Creative Commons Attribution License, which permits unrestricted use, distribution, and reproduction in any medium, provided the original work is properly cited.

\begin{abstract}
The multiple risks associated with methamphetamine use are of serious concern for women. These risks and consequences are magnified during pregnancy. This secondary analysis of a parent study compared 26 pregnant to 356 nonpregnant women in Cape Town, South Africa, on selected demographic, psychosocial, and HIV-risk domains to identify their treatment service needs. Proportionally, more pregnant than nonpregnant women are using methamphetamine, $P=.01$, although a very high rate of women used methamphetamine. Women reported similar monthly rates of sexual intercourse, but pregnant women were significantly less likely to report condom use, $P<.0001$, maintaining their risky behavior. Both groups reported elevated Center for Epidemiological Studies Depression Scale CES-D means, suggesting a need for depression treatment. Results demonstrate a pervasive need for women's comprehensive treatment, regardless of pregnancy status. Moreover, findings support the urgent need for women-focused and pregnancy-specific treatment services for methamphetamine use. Finally, a job-skills training/employment component focus is suggested.
\end{abstract}

\section{Introduction}

Cape Town, South Africa is experiencing a devastating level of methamphetamine use, with an estimated $7 \%$ of the adult population reporting the use of this drug $[1,2]$ (locally referred to as "tik"). While methamphetamine use is cause for concern in both sexes, South African social history and structure may provide a context that makes women, especially women of color who live in the township communities, Black (African and Xhosa-speaking) and Coloured (mixed racial ancestry and Afrikaans-speaking), vulnerable to intersecting risks [1-4]. If the woman remains untreated for her methamphetamine use, and then gets pregnant, the adverse consequences are likely to be exacerbated by continued drug use.

Not only is dependence a danger for both pregnant and nonpregnant South African women who use methamphetamine, but use also increases risk of exposure to sexual risk behavior, sexual violence, and HIV, which co-occur with methamphetamine use [3-7].

Similar to the use of other substances, women typically begin using methamphetamine before they become pregnant. Once pregnant, they are often unable to stop using. In South Africa, women who live in poor communities do not usually seek antenatal care, are not very informed about drug treatment, are afraid of stigma from health care providers, and are especially vulnerable to drug-related sexual risk behaviors [7-9]. In addition to the maternal vulnerabilities associated with methamphetamine misuse, prenatal stimulant exposure has been associated with fullterm birth but small gestational age [10], a risk factor for later developmental problems [11].

In Black and Coloured women in South Africa, the intersection of drug use, particularly methamphetamine use, HIV risk behaviors, and unplanned pregnancy must be addressed to improve the lives of these women and their 
children. Facing a methamphetamine epidemic, Cape Town is especially challenged with how to best reduce drug use in childbearing-age women who often do not enter formal drug treatment services.

To develop effective women-specific drug treatment services designed to meet the particular needs of South African women, it is necessary to first examine the presenting issues that pregnant and nonpregnant drug users face. This secondary analysis of a parent study addresses this need by examining the baseline characteristics of pregnant and nonpregnant female drug users who signed informed consent to participate in an adapted evidence-based womenfocused HIV behavioral intervention: the Western Cape Women's Health CoOp. Specifically, we compared pregnant and nonpregnant women on a priori selected baseline variables that were collected as a part of the main study. These baseline variables encompassed demographic, psychosocial, and HIV-risk domains to identify their shared and unique profiles of service needs.

\section{Methods}

2.1. Parent Study. The Western Cape Women's Health CoOp is an on-going community-based randomized control trial in Cape Town, South Africa that compares the effectiveness of a women-focused HIV behavioral intervention empowering women to reduce substance use, sexual risk, and victimization relative to two control conditions. The Western Cape Women's Health CoOp intervention was adapted from the original North Carolina Women's CoOp (an HIV intervention) that focused on empowering women to reduce their drug use and sexual risk behaviors [12]. The original Women's CoOp was culturally adapted for use among vulnerable sex-trading women in Pretoria, South Africa, to include a component on drug-related gender-based violence that focused on addressing sexual risk among vulnerable South African women [13]. Further changes in Cape Town for vulnerable women were piloted for group process [4].

2.2. Recruitment. Recruitment for study participation involved outreach that was conducted in targeted communities, namely, poor, mainly Black and Coloured communities surrounding the airport in Cape Town. A detailed sampling plan took into account the number of inhabitants of each community to help calculate the desired number of women to be recruited from that community. A targeted sampling plan was used to balance recruitment communities (i.e., outreach zones), and field staff worked in pairs to recruit study participants. Staff canvassed these streets and local hang-out spots frequented by women who use alcohol and other drugs and posted fliers and distributed leaflets to market the study. The field staff then approached and engaged women and verbally requested permission to administer a brief screening instrument to determine whether they were eligible to participate in the study. Recruitment began in September 2008 and ended in January 2011.

2.3. Participants. To be eligible, participants had to provide informed consent, be female and between the ages of 18 and
33 , live in one of the target communities, report using at least two drugs once per week for the past 3 months, and report being sexually active with a male partner in the past month. At the time this smaller secondary study was conducted, a total of 382 participants were randomized into one of the study conditions, and their data are included in this analysis. Based on a pregnancy test administered at study entry, it was determined that 26 women were pregnant while 356 women were nonpregnant.

2.4. Measures. The Western Cape Women's Health CoOp Revised Risk Behavior Assessment (RRBA), adapted from the RRBA [14] was administered at study entry via computerassisted participant interviews. The RRBA has 10 sections that contain questions about demographics and social characteristics, nutrition/health knowledge, alcohol use, drug use, drug injecting, sexual behavior, power and empowerment, conflict and victimization (stigma and vulnerability), obstetrical/physical/mental health, and HIV. The 20-item Center for Epidemiological Studies Depression Scale (CESD) was used to determine the depressive symptom intensity experienced by these women $[15,16]$. The CES-D also has been validated in Cape Town, South African women. Scores range from 0 to 60. A score of 16 in the United States and in South Africa indicates high risk for clinical depression [16, 17]. Pregnancy and self-reported drug use were confirmed with urine testing.

2.5. Statistical Analysis. Welch's $t$ test assuming unequal population variances and Satterthwaite's approximation for degrees of freedom was employed to analyze the continuous outcome measures. Because the sample sizes in the cells was disproportionate, and sometimes small for the pregnant women, the cross-tabulation tables were therefore sparse, so exact test statistics were used to conduct the goodness-of-fit tests for the categorical outcomes.

\section{Results}

3.1. Participant Characteristics. The total sample (Table 1) was predominantly Coloured (63.6\%), in their early 20 s, single, and having completed, on average, less than the 12 years required for graduation from high school. While few of the women were employed (9.7\%), more than three-quarters indicated that they have skills for employment. They had, on average, two children living with them. More than $1 / 3$ had spent time in prison. Finally, the elevated mean score on the CES-D would strongly suggest that a substantial percentage of these women were currently experiencing significant depressive symptoms.

3.1.1. Alcohol and Drug Use. Table 1 shows that past-month drug use differed by pregnancy status only for methamphetamine ("tik") use, with a larger proportion of pregnant than nonpregnant women reporting methamphetamine use (92.3\% versus $66.9 \% ; P=.01)$. Use of alcohol $(91.7 \%)$ and marijuana, or "dagga," (73.6\%) was reported by an overwhelming majority of both groups. In contrast, both 
Table 1: Demographic and Background Characteristics of Pregnant and Nonpregnant Women $(N=382)$.

\begin{tabular}{|c|c|c|c|c|c|}
\hline Measure & $\begin{array}{l}\text { Total sample } \\
(N=382)\end{array}$ & $\begin{array}{l}\text { Pregnant women } \\
\quad(n=26)\end{array}$ & $\begin{array}{l}\text { Nonpregnant women } \\
\quad(n=356)\end{array}$ & $\begin{array}{l}\text { Test statistic }(t(d f) \\
\left.\quad \text { or } \chi^{2}(d f)\right)\end{array}$ & $P$ \\
\hline \multicolumn{6}{|c|}{ Mean $(\mathrm{SD})$ or $n(\%)$ or $n / N(\%)$} \\
\hline \multicolumn{6}{|l|}{$\begin{array}{l}\text { Demographics and Social } \\
\text { characteristics }\end{array}$} \\
\hline Age & $23.1(4.2)$ & $22.7(3.6)$ & $24.3(4.3)$ & $t(30)=-2.22$ & .03 \\
\hline \multicolumn{6}{|l|}{ Race } \\
\hline Black & $139(36.4 \%)$ & $5(19.2 \%)$ & $134(37.6 \%)$ & $\chi^{2}(1)=3.55$ & .09 \\
\hline Coloured & $243(63.6 \%)$ & $21(80.8 \%)$ & $222(62.4 \%)$ & & \\
\hline $\begin{array}{l}\text { Mean years of education } \\
\text { completed }\end{array}$ & $9.3(1.9)$ & $9.0(2.2)$ & $9.3(1.9)$ & $t(28)=-0.69$ & .49 \\
\hline \multicolumn{6}{|l|}{ Marital status } \\
\hline Single & $353(92.4 \%)$ & $24(92.3 \%)$ & $329(92.4 \%)$ & $\chi^{2}(1)=0.00$ & 1.0 \\
\hline Married & $29(7.6 \%)$ & $2(7.7 \%)$ & $27(7.6 \%)$ & & \\
\hline Have a main sexual partner & $359(94.0 \%)$ & $24(92.3 \%)$ & $335(94.1 \%)$ & $\chi^{2}(1)=0.14$ & .66 \\
\hline \multicolumn{6}{|l|}{ Economic status } \\
\hline Employed & $37(9.7 \%)$ & $0(0.0 \%)$ & $37(10.4 \%)$ & $\chi^{2}(1)=3.00$ & .16 \\
\hline Have skills for employment & $290(75.9 \%)$ & $20(76.9 \%)$ & $270(75.8 \%)$ & $\chi^{2}(1)=0.02$ & 1.0 \\
\hline $\begin{array}{l}\text { Mean number of children living } \\
\text { with participant }\end{array}$ & $\begin{array}{l}2.0(1.7) \\
(n=351)\end{array}$ & $\begin{array}{l}2.1(1.1) \\
(n=17)\end{array}$ & $\begin{array}{l}2.0(1.7) \\
(n=325)\end{array}$ & $t(20)=0.05$ & .96 \\
\hline \multicolumn{6}{|l|}{ Legal history } \\
\hline Ever spent time in prison & $142(37.2 \%)$ & $9(34.6 \%)$ & $133(37.4 \%)$ & $\chi^{2}(1)=0.08$ & .84 \\
\hline \multicolumn{6}{|l|}{ Violence exposure } \\
\hline Ever been physically hurt & $171(44.8 \%)$ & $8(30.8 \%)$ & $163(45.8 \%)$ & $\chi^{2}(1)=2.21$ & .16 \\
\hline $\begin{array}{l}\text { Ever forced to perform sexual } \\
\text { acts }\end{array}$ & $89(23.3 \%)$ & $6(23.1 \%)$ & $83(23.3 \%)$ & $\chi^{2}(1)=0.001$ & 1.0 \\
\hline \multicolumn{6}{|l|}{ Risk factors for substance abuse } \\
\hline $\begin{array}{l}\text { Depressive symptom severity: } \\
\text { mean CES-D score in past week }\end{array}$ & $28.4(12.2)$ & $29.7(9.9)$ & $29.4(12.2)$ & $t(31)=0.16$ & .87 \\
\hline $\begin{array}{l}\text { Family members use drugs } \\
\text { and/or alcohol too much }\end{array}$ & $289(75.7 \%)$ & $22(84.6 \%)$ & $267(75.0 \%)$ & $\chi^{2}(1)=1.22$ & .35 \\
\hline Maternal history of alcohol use & $183(47.9 \%)$ & $12(46.2 \%)$ & $171(48.0 \%)$ & $\chi^{2}(1)=0.03$ & 1.0 \\
\hline $\begin{array}{l}\text { During the past } 30 \text { days, did your } \\
\text { main partner get drunk }\end{array}$ & $211 / 359(58.8 \%)$ & $13 / 24(54.2 \%)$ & $198 / 335(59.1 \%)$ & $\chi^{2}(1)=0.23$ & .67 \\
\hline $\begin{array}{l}\text { During the past } 30 \text { days, did your } \\
\text { main partner use drugs }\end{array}$ & $232 / 359(64.6 \%)$ & $13 / 24(54.2 \%)$ & $219 / 335(65.4 \%)$ & $\chi^{2}(1)=1.23$ & .28 \\
\hline \multicolumn{6}{|l|}{$\begin{array}{l}\text { Alcohol and drug use and drug } \\
\text { injecting }\end{array}$} \\
\hline Methamphetamine (tik) use & $262(68.6 \%)$ & $24(92.3 \%)$ & $238(66.9 \%)$ & $\chi^{2}(1)=7.29$ & .01 \\
\hline Drink alcohol & $341 / 372(91.7 \%)$ & $23 / 26(88.5 \%)$ & $318 / 346(91.9 \%)$ & $\chi^{2}(1)=0.38$ & .47 \\
\hline How often do you drink alcohol & $(n=372)$ & $(n=26)$ & $(n=346)$ & & \\
\hline Never & $31(8.3 \%)$ & $3(11.5 \%)$ & $28(8.1 \%)$ & & \\
\hline Monthly or less & $90(24.2 \%)$ & $4(15.4 \%)$ & $86(24.9 \%)$ & & \\
\hline 2-4 times per month & $101(27.2 \%)$ & $12(46.2 \%)$ & $89(25.7 \%)$ & $\chi^{2}(4)=6.26$ & .14 \\
\hline 2-3 times per week & $114(30.7 \%)$ & $5(19.2 \%)$ & $109(31.5 \%)$ & & \\
\hline 4 or more times per week & $36(9.7 \%)$ & $2(7.7 \%)$ & $34(9.8 \%)$ & & \\
\hline Marijuana (dagga) use & $281(73.6)$ & $17(65.4 \%)$ & $264(74.2 \%)$ & $\chi^{2}(1)=0.96$ & .36 \\
\hline Rock use & $12(3.1 \%)$ & $1(3.8 \%)$ & $11(3.1 \%)$ & $\chi^{2}(1)=0.05$ & .58 \\
\hline Cocaine use & $2(0.5 \%)$ & $0(0 \%)$ & $2(0.6 \%)$ & $\chi^{2}(1)=0.15$ & 1.0 \\
\hline
\end{tabular}


Table 1: Continued.

\begin{tabular}{|c|c|c|c|c|c|}
\hline Measure & $\begin{array}{l}\text { Total sample } \\
(N=382)\end{array}$ & $\begin{array}{l}\text { Pregnant women } \\
\quad(n=26)\end{array}$ & $\begin{array}{l}\text { Nonpregnant women } \\
\quad(n=356)\end{array}$ & $\begin{array}{l}\text { Test statistic }(t(d f) \\
\left.\quad \text { or } \chi^{2}(d f)\right)\end{array}$ & $P$ \\
\hline Heroin use & $13(3.4 \%)$ & $0(0 \%)$ & $13(3.7 \%)$ & $\chi^{2}(1)=0.98$ & 1.0 \\
\hline Mandrax (white pipe) use & $98(25.7 \%)$ & $8(30.8 \%)$ & $90(25.3 \%)$ & $\chi^{2}(1)=0.38$ & .50 \\
\hline Ever injected & $3(0.8 \%)$ & $0(0 \%)$ & $3(0.84 \%)$ & $\chi^{2}(1)=0.22$ & 1.0 \\
\hline $\begin{array}{l}\text { Participant thinks she has an } \\
\text { alcohol problem }\end{array}$ & $52(13.6 \%)$ & $2(7.7 \%)$ & $50(14.0 \%)$ & $\chi^{2}(1)=0.83$ & .55 \\
\hline $\begin{array}{l}\text { Participant thinks she has a drug } \\
\text { problem }\end{array}$ & $244(63.9 \%)$ & $16(61.5 \%)$ & $228(64.0 \%)$ & $\chi^{2}(1)=0.07$ & .83 \\
\hline \multicolumn{6}{|l|}{ Drug treatment history } \\
\hline Ever been to drug treatment & $34(8.9 \%)$ & $3(11.5 \%)$ & $31(8.7 \%)$ & $\chi^{2}(1)=0.24$ & .72 \\
\hline \multicolumn{6}{|l|}{$\begin{array}{l}\text { Reasons for not entering drug } \\
\text { Treatment }\end{array}$} \\
\hline Drug treatment does not work & $100 / 348(28.7 \%)$ & $7 / 23(30.4 \%)$ & $93 / 325(28.6 \%)$ & $\chi^{2}(1)=0.03$ & .82 \\
\hline $\begin{array}{l}\text { Participant does not know where } \\
\text { to go for treatment }\end{array}$ & $95 / 349(27.2 \%)$ & $2 / 23(8.7 \%)$ & $93 / 326(28.5 \%)$ & $\chi^{2}(1)=4.27$ & .05 \\
\hline $\begin{array}{l}\text { Lack the money to pay for } \\
\text { treatment }\end{array}$ & $69 / 349(19.8 \%)$ & $2 / 23(8.7 \%)$ & $67 / 326(20.6 \%)$ & $\chi^{2}(1)=1.9$ & .28 \\
\hline \multicolumn{6}{|l|}{ Nutrition } \\
\hline \multicolumn{6}{|l|}{ Frequency of going without food } \\
\hline Never & $127(33.3 \%)$ & $6(23.1 \%)$ & $121(34.0 \%)$ & & \\
\hline Less than once a month & $87(22.8 \%)$ & $7(26.9 \%)$ & $80(22.5 \%)$ & $\chi^{2}(3)=1.36$ & .64 \\
\hline Less than once a week & $73(19.1 \%)$ & $6(23.1 \%)$ & $67(18.8 \%)$ & & \\
\hline Every week & $95(24.9 \%)$ & $7(26.9 \%)$ & $88(24.7 \%)$ & & \\
\hline \multicolumn{6}{|l|}{ Obstetrical status } \\
\hline Now pregnant & $26(6.8 \%)$ & & & & \\
\hline Seek prenatal care & & $19(73.1 \%)$ & & & \\
\hline Received prenatal care & & $9(34.6 \%)$ & & & \\
\hline \multicolumn{6}{|l|}{$\begin{array}{l}\text { Use of methamphetamine (tik) } \\
\text { while pregnant }\end{array}$} \\
\hline Never used & & $2(7.7 \%)$ & & & \\
\hline Stopped & & $0(0 \%)$ & & & \\
\hline Reduced & & $16(61.5 \%)$ & & & \\
\hline Same & & $7(26.9 \%)$ & & & \\
\hline Increased & & $1(3.9 \%)$ & & & \\
\hline \multicolumn{6}{|l|}{ Use of alcohol while pregnant } \\
\hline Never used & & $2(7.7 \%)$ & & & \\
\hline Stopped & & $9(34.6 \%)$ & & & \\
\hline Reduced & & $10(38.5 \%)$ & & & \\
\hline Same & & $5(19.2 \%)$ & & & \\
\hline \multicolumn{6}{|l|}{$\begin{array}{l}\text { Use of marijuana (dagga) while } \\
\text { pregnant }\end{array}$} \\
\hline Never used & & $5(19.2 \%)$ & & & \\
\hline Stopped & & $3(11.5 \%)$ & & & \\
\hline Reduced & & $13(50.0 \%)$ & & & \\
\hline Same & & $4(15.4 \%)$ & & & \\
\hline Increased & & $1(3.9 \%)$ & & & \\
\hline
\end{tabular}

Notes. Probability values for $\chi^{2}$ tests of significance are based on exact methods. Percentages are within their respective sample. 
TABLE 2: Sexual behavior of pregnant and nonpregnant women $(N=382)$.

\begin{tabular}{|c|c|c|c|c|c|}
\hline Measure & $\begin{array}{l}\text { Total sample } \\
(N=382)\end{array}$ & $\begin{array}{l}\text { Pregnant women } \\
\quad(n=26)\end{array}$ & $\begin{array}{l}\text { Nonpregnant women } \\
\quad(n=356)\end{array}$ & $\begin{array}{c}\text { Test statistic }(t(d f) \text { or } \\
\left.\chi^{2}(d f)\right)\end{array}$ & $P$ \\
\hline Last sex was with a man & $374(97.9 \%)$ & $26(100 \%)$ & $348(97.8 \%)$ & $\chi^{2}(1)=0.60$ & 1.0 \\
\hline $\begin{array}{l}\text { At last sex act, participant used } \\
\text { drugs or alcohol use before or } \\
\text { during sex }\end{array}$ & $202(52.9 \%)$ & $11(42.3 \%)$ & $191(53.7 \%)$ & $\chi^{2}(1)=1.25$ & .31 \\
\hline Mean age at first vaginal sex & $16.2(2.73)$ & $16.2(1.63)$ & $16.3(2.95)$ & $t(38)=-0.19$ & .85 \\
\hline First vaginal sex was willing & $307(80.4 \%)$ & $22(84.6 \%)$ & $285(80.1 \%)$ & $\chi^{2}(1)=0.32$ & .80 \\
\hline Condom used first time & $117(30.6 \%)$ & $12(46.2 \%)$ & $105(29.5 \%)$ & $\chi^{2}(1)=3.17$ & .08 \\
\hline $\begin{array}{l}\text { Past } 30 \text { day sex with main } \\
\text { partner }\end{array}$ & $349 / 359(97.2 \%)$ & $24 / 24(100 \%)$ & $325 / 335(97.0 \%)$ & $\chi^{2}(1)=0.74$ & 1.0 \\
\hline $\begin{array}{l}\text { Mean of sex partners in past } 30 \\
\text { days }\end{array}$ & $1.29(2.0)$ & $1.11(0.4)$ & $1.36(2.4)$ & $t(199)=-1.57$ & .12 \\
\hline $\begin{array}{l}\text { Mean times of sex with main } \\
\text { partner in past } 30 \text { days }\end{array}$ & $8.09(6.90)$ & $6.04(7.96)$ & $8.24(6.81)$ & $t(25)=-1.29$ & .25 \\
\hline $\begin{array}{l}\text { Mean times of condom use with } \\
\text { sex with main partner in past } 30 \\
\text { days }\end{array}$ & $1.93(4.29)$ & $0.26(0.92)$ & $2.04(4.40)$ & $t(129)=-5.75$ & $<.0001$ \\
\hline $\begin{array}{l}\text { Drugs and alcohol leads to sex } \\
\text { risk }\end{array}$ & $84(22.0 \%)$ & $7(26.9 \%)$ & $77(21.6 \%)$ & $\chi^{2}(1)=0.40$ & .62 \\
\hline $\begin{array}{l}\text { Trading sex for money in past } 6 \\
\text { months }\end{array}$ & $31 / 58(53.5 \%)$ & $3 / 5(60 \%)$ & $28 / 53(52.8 \%)$ & $\chi^{2}(1)=0.09$ & 1.0 \\
\hline $\begin{array}{l}\text { Trading sex for drugs in past } 6 \\
\text { months }\end{array}$ & $23 / 58(39.7 \%)$ & $1 / 5(20.0 \%)$ & $22 / 53(41.5 \%)$ & $\chi^{2}(1)=0.88$ & .64 \\
\hline \multicolumn{6}{|l|}{ Last time had sex: } \\
\hline $48 \mathrm{hrs}$ & $123(32.2 \%)$ & $10(38.5 \%)$ & $113(31.7 \%)$ & & \\
\hline $3-7$ days & $157(41.1 \%)$ & $11(42.3 \%)$ & $146(41.0 \%)$ & $\chi^{2}(2)=0.93$ & .89 \\
\hline In last 8-30 days & $102(26.7 \%)$ & $5(19.2 \%)$ & $97(27.3 \%)$ & & \\
\hline $\begin{array}{l}\text { At last sexual encounter the } \\
\text { woman participant was willing }\end{array}$ & $368(96.3 \%)$ & $26(100 \%)$ & $342(96.0 \%)$ & $\chi^{2}(1)=1.06$ & .61 \\
\hline
\end{tabular}

Note. Probability values for $\chi^{2}$ tests of significance are based on exact methods.

groups reported infrequent use of most other drugs, including heroin and cocaine. Almost two-thirds of the sample indicated they believed they had a drug problem; only a small percentage of the sample reported they had an alcohol problem. These statements appear equally true for both the pregnant as well as the nonpregnant sample.

3.1.2. Sexual Behavior. Almost all participants had a main sex partner (Table 1). Table 2 reveals that more than half the sample had used drugs or alcohol before or during sex, and that more than half had traded sex for money, and more than one-third had traded sex for drugs in the past 30 days. The mean number of sex partners in the past 30 days was quite low $(1.29(\mathrm{SD}=2.0))$, although more than two-thirds indicated they had engaged in sex with a casual partner. While over $90 \%$ of both groups reported having sex with their main partner in the past month, pregnant women reported fewer times of condom use in the past month than did nonpregnant women $(.26$ versus $2.04, P<.0001)$.

In the pregnant sample, only $34.6 \%$ of women received prenatal care, although $73.1 \%$ sought such care (Table 1). However, it should be noted that a self-report of receipt of prenatal care could include as little as setting up a delivery date. More than $50 \%$ of the women indicated that they had reduced or stopped their alcohol, dagga, and methamphetamine use; however, clinically concerning percentages of women were still using these substances during pregnancy (Table 1). This statement is particularly true for methamphetamine, for which more than $30 \%$ of the pregnant sample reported that their use of methamphetamine was the same frequency or more frequent than before they became pregnant.

3.1.3. Needs Assessment. Table 3 indicates that the most requested services included services in the areas of employment $(86.7 \%)$, financial assistance $(82.5 \%)$, and housing (68.3\%); medical (53.4\%), transportation (48.4\%), alcohol/drug services (47.6\%), school (45.8\%), and HIV/STD testing $(42.9 \%)$ all hover around $50 \%$. Approximately onequarter of the sample expressed a need for sexual abuse and/or legal assistance services. Mental health assistance was least requested (19.1\%). Finally, it should be noted that a greater proportion of pregnant than nonpregnant women wanted educational assistance $(65.4 \%$ versus $44.4 \%$; $P=$ $.04)$. 
TABLE 3: Areas in which participants expressed a need for a social service $(N=382)$.

\begin{tabular}{|c|c|c|c|c|c|}
\hline Measure & $\begin{array}{c}\text { Total sample } \\
(N=382)\end{array}$ & $\begin{array}{l}\text { Pregnant women } \\
(n=26)\end{array}$ & $\begin{array}{c}\text { Nonpregnant } \\
\text { women }(n=356)\end{array}$ & $\chi^{2}$ & $P$ \\
\hline Service area & \multicolumn{5}{|c|}{$n(\%)$} \\
\hline Employment & $331(86.7 \%)$ & $21(80.8 \%)$ & $310(87.1 \%)$ & 0.83 & .37 \\
\hline Financial assistance & $315(82.5 \%)$ & $19(73.1 \%)$ & $296(83.2 \%)$ & 1.70 & .19 \\
\hline Housing & $261(68.3 \%)$ & $17(65.4 \%)$ & $244(68.5 \%)$ & 0.11 & .83 \\
\hline Medical & $204(53.4 \%)$ & $15(57.7 \%)$ & $189(53.1 \%)$ & 0.21 & .69 \\
\hline Transportation & $185(48.4 \%)$ & $12(46.2 \%)$ & $173(48.6 \%)$ & 0.06 & .84 \\
\hline Alcohol/drug services & $182(47.6 \%)$ & $10(38.5 \%)$ & $172(48.3 \%)$ & 0.94 & .42 \\
\hline School & $175(45.8 \%)$ & $17(65.4 \%)$ & $158(44.4 \%)$ & 4.31 & .04 \\
\hline HIV/STD testing & $164(42.9 \%)$ & $8(30.8 \%)$ & $156(43.8 \%)$ & 1.68 & .22 \\
\hline Child care & $113(29.6 \%)$ & $7(26.9 \%)$ & $106(29.8 \%)$ & 0.09 & .83 \\
\hline Sexual abuse & $99(25.9 \%)$ & $4(15.4 \%)$ & $95(26.7 \%)$ & 1.61 & .25 \\
\hline Legal assistance & $93(24.4 \%)$ & $5(19.2 \%)$ & $88(24.7 \%)$ & 0.40 & .64 \\
\hline Mental health & $73(19.1 \%)$ & $2(7.7 \%)$ & $71(19.9 \%)$ & 2.35 & .19 \\
\hline
\end{tabular}

Notes. $d f=1$ for all $\chi^{2}$ tests of significance. Probability values are based on exact methods.

\section{Discussion}

The study has several major findings. First, there is the concerning rate of methamphetamine use among pregnant women compared with nonpregnant women. The fact that over $90 \%$ of the pregnant women reported recently using methamphetamine is consistent with another recent study in Cape Town, which showed that among a group of pregnant women who smoked tobacco, up to $78 \%$ reported methamphetamine use [18]. These results are also consistent with other reports of high rates of methamphetamine use observed in Cape Town among the general population, its women, and its out-of-school young women between 13 to 20 years old $[4,8]$. Taken together, the past and current data highlight the urgent need to develop and implement effective women-focused interventions to reduce this epidemic. The high rate of methamphetamine use among pregnant women may also be a reflection of the relationship between methamphetamine use and sexual risk behavior, which can result in pregnancy. On a positive note, the majority of the pregnant women made attempts to reduce their drug use after learning that they were pregnant, which is an encouraging sign. However, more than $30 \%$ of the pregnant sample either used at the same level or increased use of methamphetamine. Given the potentially adverse impact of stimulants on fetal brain development, particularly in the context of multiple environmental risk factors, there is a clear need for prevention initiatives in the Western Cape of South Africa, similar in scope and focus to efforts for informing the public about fetal alcohol spectrum disorders.

The second major finding of this secondary analysis is the pervasive need for comprehensive treatment for pregnant Black and Coloured women in Cape Town, South Africa. Although these women have myriad needs, the pregnant women in this sample necessarily required medical and obstetrical care. The literature from South Africa suggests that over the 16 years since National Health System has provided free antenatal and intrapartial care to all uninsured women, many women have not been accessing or have been underutilizing care before delivery [19]. The reasons underlying this underutilization are complex and include structural barriers (e.g., inconvenient hours of clinic operation, inability to take time off from work, too long a wait to be seen, lack of child care, and/or transportation); relationship issues (e.g., unstable relationship with the father of the baby); psychological factors (e.g., unwanted pregnancy, pregnancy denial); lack of education as to the need for prenatal health care; negative interactions with the medical professionals [20-24]. The current findings, in context with the prior literature, suggest that women want medical care as well as drug and alcohol treatment, yet interventions must be implemented where they can be reached and at multiple levels to concurrently address the structural barriers to care, improve the actual care these women receive, and reduce the perceived and actual stigma and discrimination the women feel and encounter.

The third finding of note is that the pregnant women had a lower rate of condom use than did the nonpregnant women. This result suggests that a significant proportion of methamphetamine-using Black and Coloured women consider condoms to serve the primary role of birth control rather than of disease prevention. If this conclusion is supported by future research, community outreach efforts need to be made to educate this high-risk population regarding the crucial role that condoms can play in HIV/sexually transmitted infection prevention.

Finally, it is notable that these women made a clear distinction between mental health services and alcohol/drug services. Fewer than 1 in 5 women expressed a need for mental health services, despite the CES-D mean score being almost twice that of the clinical cutoff used previously in low-income US and South African women. Although increased depressive symptoms are associated with being of color, lower educational attainment, and low income; having 
substandard living conditions; living in stressful neighborhoods; possibly, lacking support of a partner [17], this finding underscores the need for intervention to ameliorate the symptoms of depression while concurrently treating drug addiction.

In contrast to the low self-reported need for mental health services, almost 1 in 2 women expressed a need for alcohol/drug services. Moreover, the most pressing needs expressed were for economic support, with more than threequarters of the women wanting employment and financial aid; housing only slightly trailed the former two needs. These conclusions appear to be equally valid for the pregnant women as for the nonpregnant women.

\section{Study Limitations}

As with all studies, the present study has its limitations. First, it involved a preliminary and secondary analysis to the aims from ongoing larger Western Cape Women's Health CoOp project, which has a focus on HIV prevention that is different from the present project. Thus, the inclusion and exclusion criteria of the parent project may have adversely impacted the ability to recruit a representative sample of Black and Coloured South African women. Second, the extent to which these results generalize to the larger population of Black and Coloured South African women is unknown. Third, because the primary focus of the parent project was not pregnancy and substance use, the number of respondents who were pregnant was relatively low in comparison to the size of the nonpregnant sample. Fourth, the RRBA was focused on collecting a wide variety of information, not all of which was maximally relevant to pregnant women. Despite the limitations, the findings provide considerable initial information on the similarities and unique issues for pregnant and nonpregnant Black and Coloured South African women.

\section{Conclusions}

Study findings strongly support two conclusions. First, the widespread use of methamphetamine in pregnant Black and Coloured South African women indicate an urgent need for the development and implementation of comprehensive treatment programs to address methamphetamine use (as well as other co-occurring substance use) in these women. Second, findings suggest that both common and unique issues between pregnant and nonpregnant women must be addressed when developing and adapting comprehensive treatments for substance-using Black and Coloured South African women of childbearing age. Notably, the dismal circumstances that impact the health and well-being of many of these women (and their children) are unlikely to change until they are provided with women-centered medical and obstetrical care and drug treatment. Moreover, programs should include employment or job-skills training so that these women can break the cycle of trading sex for money and drugs.

\section{Acknowledgments}

Funding for this study and the parent study was provided by the Eunice Kennedy Shriver National Institute of Child Health and Human Development (NICHD) R01 HD058320 (PI: Dr. Wendee M. Wechsberg). NICHD had no further role in study design; in the collection, analysis, and interpretation of data; in the writing of the report.

\section{References}

[1] K. Morris and C. Parry, "South African methamphetamine boom could fuel further HIV," The Lancet Infectious Diseases, vol. 6, no. 8, p. 471, 2006.

[2] C. Kapp, "Crystal meth boom adds to South Africa's health challenges," Lancet, vol. 371, no. 9608, pp. 193-194, 2008.

[3] W. M. Wechsberg, W. Luseno, K. Riehman, R. Karg, F. Browne, and C. Parry, "Substance use and sexual risk within the context of gender inequality in South Africa," Substance Use and Misuse, vol. 43, no. 8-9, pp. 1186-1286, 2008.

[4] W. M. Wechsberg, W. K. Luseno, R. S. Karg et al., "Alcohol, cannabis, and methamphetamine use and other risk behaviours among Black and Coloured South African women: a small randomized trial in the Western Cape," International Journal of Drug Policy, vol. 19, no. 2, pp. 130-139, 2008.

[5] K. Wood, F. Maforah, and R. Jewkes, "'He forced me to love him': putting violence on adolescent sexual health agendas," Social Science and Medicine, vol. 47, no. 2, pp. 233-242, 1998.

[6] L. Ackermann and G. W. De Klerk, "Social factors that make South African women vulnerable to HIV infection," Health Care for Woman International, vol. 23, no. 2, pp. 163-172, 2002.

[7] W. M. Wechsberg, W. K. Luseno, and W. K. Lam, "Violence against substance-abusing South African sex workers: intersection with culture and HIV risk," AIDS Care, vol. 17, pp. S55-S64, 2005.

[8] W. M. Wechsberg, H. E. Jones, W. A. Zule et al., "Methamphetamine ("tik") use and its association with condom use among out-of-school females in Cape Town, South Africa," American Journal of Drug and Alcohol Abuse, vol. 36, no. 4, pp. 208-213, 2010.

[9] L. Myer and A. Harrison, "Why do womn seek antenatal care late? Perspectives from rural South Africa," Journal of Midwifery and Women's Health, vol. 48, no. 4, pp. 268-272, 2003.

[10] M. S. Paz, L. M. Smith, L. L. LaGasse et al., "Maternal depression and neurobehavior in newborns prenatally exposed to methamphetamine," Neurotoxicology and Teratology, vol. 31, no. 3, pp. 177-182, 2009.

[11] B. Van Kessel-Feddema, M. Sondaar, M. De Kleine, C. Verhaak, and A. Van Baar, "Concordance between school outcomes and developmental follow-up results of very preterm and/or low birth weight children at the age of 5 years," European Journal of Pediatrics, vol. 166, no. 7, pp. 693-699, 2007.

[12] W. M. Wechsberg, W. K. K. Lam, W. A. Zule, and G. Bobashev, "Efficacy of a woman-focused intervention to reduce HIV risk and increase self-sufficiency among African American crack abusers," American Journal of Public Health, vol. 94, no. 7, pp. 1165-1173, 2004. 
[13] W. M. Wechsberg, W. K. Luseno, W. K. K. Lam, C. D. H. Parry, and N. K. Morojele, "Substance use, sexual risk, and violence: HIV prevention intervention with sex workers in pretoria," AIDS and Behavior, vol. 10, no. 2, pp. 131-137, 2006.

[14] W. M. Wechsberg, Revised Risk Behavior Assessment (RBA), Part I and Part II, Research Triangle Institute, Research Triangle Park, NC, USA, 1998.

[15] C. K. Cheung and C. Bagley, "Validating an American scale in Hong Kong: the Center for Epidemiological Studies Depression Scale (CES-D)," The Journal of psychology, vol. 132, no. 2, pp. 169-186, 1998.

[16] L. S. Radloff, "The CES-D scale: a self-report depression scale for research in the general population," Applied Psychological Measurement, vol. 1, no. 2, pp. 385-401, 1977.

[17] R. Hamad, L. C. H. Fernald, D. S. Karlan, and J. Zinman, "Social and economic correlates of depressive symptoms and perceived stress in South African adults," Journal of Epidemiology and Community Health, vol. 62, no. 6, pp. 538544, 2008.

[18] K. Everett-Murphy, K. Steyn, C. Mathews et al., "The effectiveness of adapted, best practice guidelines for smoking cessation counseling with disadvantaged, pregnant smokers attending public sector antenatal clinics in Cape Town, South Africa," Acta obstetricia et gynecologica Scandinavica, vol. 89, no. 4, pp. 478-489, 2010.

[19] M. S. Westaway, E. Viljoen, G. M. Wessie, J. McIntyre, and P. A. Cooper, "Monitoring utilisation, quality \&amp; effectiveness of free antenatal care in an informal settlement in Gauteng," Curationis, vol. 21, no. 2, pp. 57-59, 1998.

[20] J. V. Larsen and A. Van Middelkoop, “The 'unbooked' mother at King Edward VIII Hospital, Durban," South African Medical Journal, vol. 62, no. 14, pp. 483-486, 1982.

[21] R. C. Pattinson and L. Rossouw, "The unbooked mother at Tygerberg Hospital. A prospective controlled study," South African Medical Journal, vol. 71, no. 9, pp. 559-560, 1987.

[22] R. A. Hamilton, T. Perlmann, and J. J. L. De Souza, "The unbooked patient. Part I. Reasons for failure to attend antenatal clinics," South African Medical Journal, vol. 71, no. 1, pp. 28-31, 1987.

[23] N. Abrahams, R. Jewkes, and Z. Mvo, "Health care-seeking practices of pregnant women and the role of the midwife in Cape town, South Africa," Journal of Midwifery and Women's Health, vol. 46, no. 4, pp. 240-247, 2001.

[24] R. Jewkes, N. Abrahams, and Z. Mvo, "Why do nurses abuse patients? Reflections from South African obstetric services," Social Science and Medicine, vol. 47, no. 11, pp. 1781-1795, 1998. 


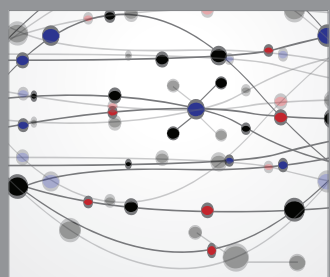

The Scientific World Journal
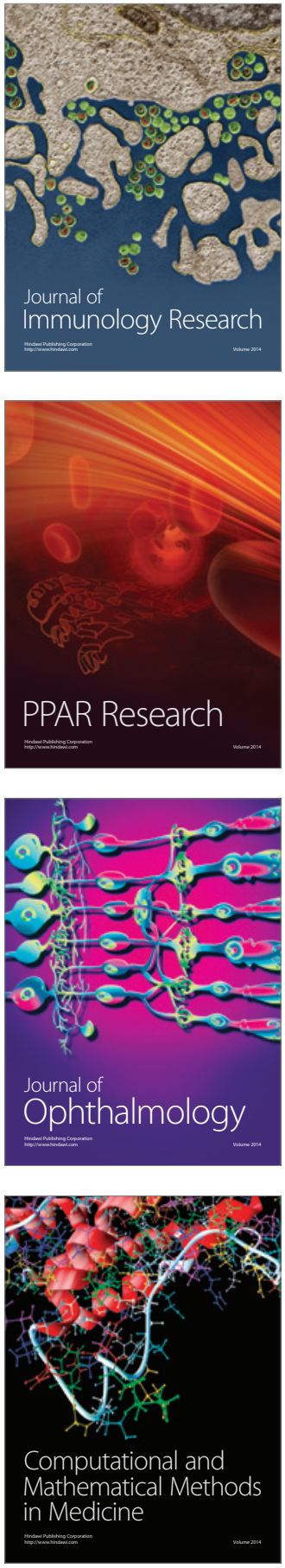

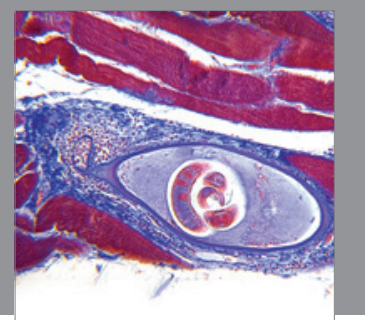

Gastroenterology

Research and Practice
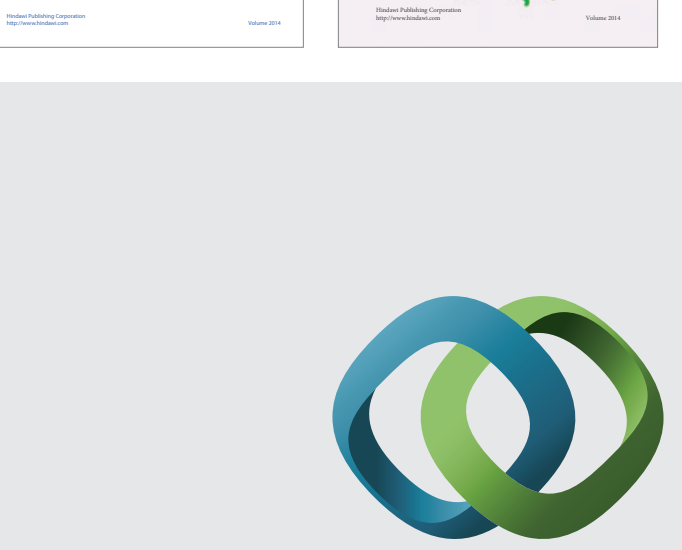

\section{Hindawi}

Submit your manuscripts at

http://www.hindawi.com
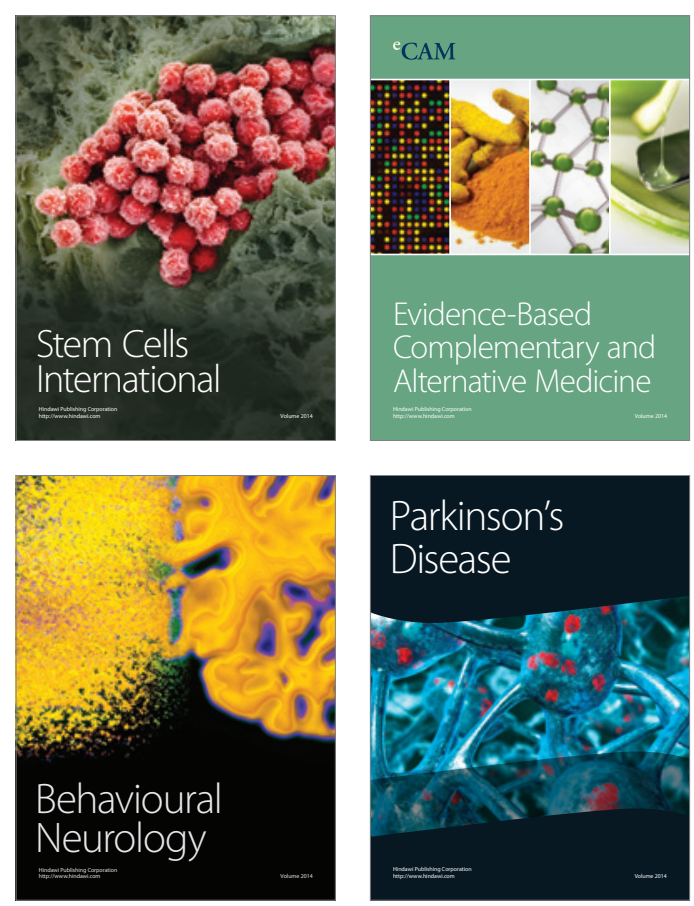

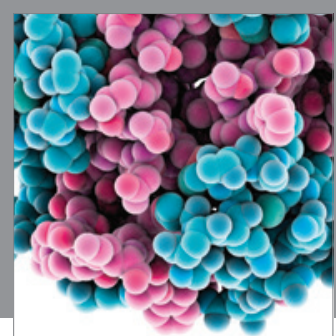

Journal of
Diabetes Research

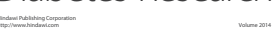

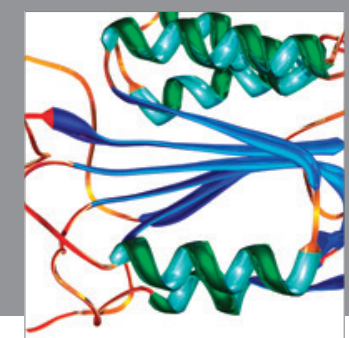

Disease Markers
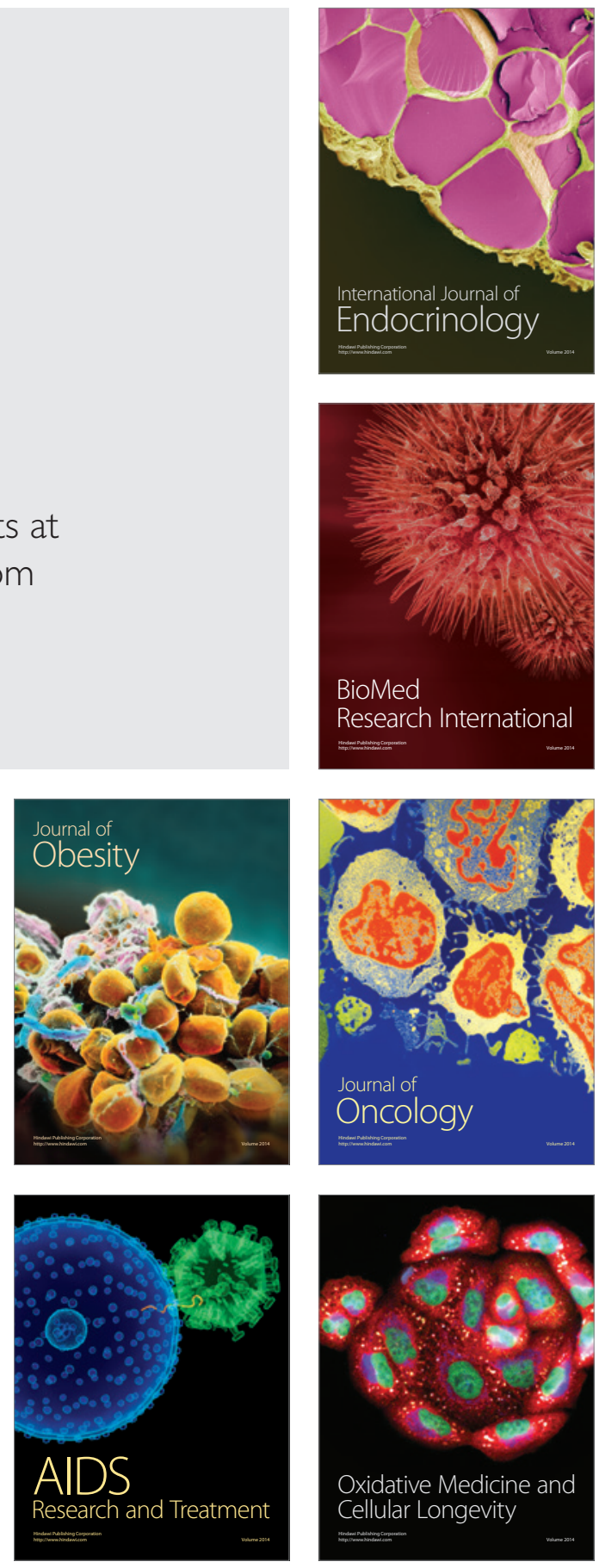